\title{
Population and Development vs Quality of Life: A Sociological Appraisal
}

Professor Emeritus of Sociology, Alzahra University, Tehran, Iran

\begin{abstract}
The two variables of population and development affect each other in an indirect manner in which when population increase happens, development is reduced. The two effectively impact quality of life. It is strongly recommended to control population in order to achieve development. Sociologists are widely responsible to create the balance of population and development. As resources are limited in each country, an organized and planned population is needed towards any development. The phenomenon development being multilateral, needs an appropriate population size. It is worth mentioning that population naturally grows, but resources for development do not. Overall, Asia, Africa, and Latin America had very high population growth rate of $2.1 \%$ between 1955 and 1975 . Fortunately, increase of literacy and education has caused population growth rates to decline in the past two decades in many parts of the developing countries. The only part of the developing world with high population growth rate is Africa in which the population will increase to over 4.2 billion by the year 2100; threatening other parts of the world. Such a situation will widely endanger quality of life.
\end{abstract}

Keywords: Population growth, Imbalanced development, Fertility and quality of life, Women's rights, Poverty decline.

\section{Introduction}

The two contexts of population and development are mutually connected with each other. Population needs to be controlled to bring about tranquility and desired quality of life. Many developing countries with high population growth rate are much far from development. On the other hand, industrial nations that started organizing their population, could reach higher standards thereof, leading to more comfort and convenience for all ages. Thus, countries must try to achieve development to reach a desired quality of life. Increasing gap between desired population, and the existing population has kept them away of accessing development __ the whole process keeps the developing nations in low quality of life. Such a stage of life deprive many age groups of many facilities such as access to wanted health, food, education, sports, recreation, housing and many more. An increasing number of countries in Asia, Africa and Latin America are in such a situation. Population and development cover population studies, the relationships between population, economy and the environment. That is, social change, and related thinking on population and public policy. The highest global population rates is more due to development peaking at $2.1 \%$ between 1955 and 1975 (World Population Prospects, 2016). The global population is still increasing, but there is a significant uncertainty about its long-term trajectory due to the changing rates of fertility and mortality (Esteban, 2013). Some other demographers predict that world population will begin to decline in the second half of the 21 st century (Damien, 2021). The score of quality of life out of 10 , is as the following for some countries.

Table 1: Quality of life Ratings in Selected Countries 2012 
Mohammad Taghi Sheykhi

Population and Development vs Quality of Life: A Sociological Appraisal

\begin{tabular}{|c|c|}
\hline Switzerland & 8.22 \\
\hline Norway & 8.09 \\
\hline Canada & 7.81 \\
\hline Austria & 7.73 \\
\hline USA & 7.38 \\
\hline China & 5.99 \\
\hline Turkey & 5.95 \\
\hline India & 5.67 \\
\hline Vietnam & 5.64 \\
\hline Bangladesh & 5.07 \\
\hline Nigeria & 4.74 \\
\hline
\end{tabular}

Source: The lottery of life, 2012.

The two areas of population and development are interrelated. While the adoption of population policies and population planning makes it possible to achieve greater development, development in turn modifies demographic indicators. This reciprocal flow first entered industrialized countries, and then gradually into developing countries. Therefore, in the conditions of uncontrolled population growth, less economic development can be achieved. Therefore, the process of population and development must ultimately be limited by natural problems (Boserup: 1981). While the world's population exceeded seven billion in 2011, urban spaces have expanded at an unprecedented rate. Population growth and the expansion of cities themselves will play an important role in how the planet Earth works, and consequently affect the quality of human life in various dimensions. This means that as natural populations grow exponentially, many natural resources are being overused; In a way, future generations will face a lack of many resources. Hence, population and development must always be planned in proportion to each other; Otherwise, human societies will face many limitations, lack of resources and so on.

\section{Method of Research}

Methodology used in the present article is of qualitative type. In that, various paradigms have been used to find out about the facts regarding pandemics during the history. Qualitative research usually studies people, events or areas in their natural settings. In finding facts for the research, the researcher engaged in careful data collection and thoughtful analysis of what was relevant. In the documentary research applied for the present research, printed and written materials were widely regarded. The research was performed as a qualitative librarytype in which the researcher had to refer to the relevant and related sources. In the current research, various documents were thoroughly investigated, and the needful inferences were made. The data fed by the investigator in the present article is hopefully reliable. Though literature on pandemics is very limited, yet the author tried to investigate many different resources in order to elicit the necessary information to build up the text.

\section{Population Growth}

Population growth patterns are related to almost all the challenges that urban society faces. At the same time, how poverty, pollution of urban spaces, how to produce energy, food, water shortage, poor health and the like, are among the consequences of population growth, and as 


\section{Mohammad Taghi Sheykhi \\ Population and Development vs Quality of Life: A Sociological Appraisal}

a result, population growth and urban expansion. Hence, population growth, while having immediate effects, also has long-term and future consequences. Therefore, development planners must always consider the population factor (population growth), and predict its growth. In this regard, demographers have been quite successful in their demographic forecasts, which are conducted every two years by the United Nations in the form of national, regional and global forecasts (United Nations: 2010). Undoubtedly, demographic issues and consequences are the most important challenges facing humanity today. The methods we adopt today will affect our own health and happiness even for future generations (Population and Development Review: 2012). One of the regions of the world that is facing the consequences of population growth decades ago is the region of Asia itself. This is what will happen to the African continent. At the same time, development in its general sense also brings with it cultural and value changes, which in turn lead to reduced population growth.

While the average population growth in Africa in 2011 was about 2.4 percent, it is 1.1 percent in Asia, 0.5 percent in North America, 1.2 percent in Latin America, zero percent in Europe and in The Oceania region is estimated at 1.2 percent per year. The low indicators of population growth in these areas are largely due to social, economic and cultural development in these areas. While high population growth in the African region itself greatly delays development on the continent, and lowers the general quality of life, African countries will face many social challenges and problems in the coming years. And will face quality of life; That is, the conditions under which massive migrations will take place.

The world's population is projected to exceed 9 billion by 2050. According to UN forecasts, this population will reach 10 billion by 2100 (United Nations: 2010). These issues and the desire to improve living standards at the same time will create a great challenge for many countries in the world. Mostly, it is the developing countries that are in this critical situation; That is, their population grows without providing sufficient resources for employment and services. In this movement, achieving a decent and satisfactory quality of life within developing countries will appear more and more. Therefore, given the 2050 population outlook, less developed countries need to adopt appropriate demographic, economic and social policies in order to meet the growing needs of their citizens.

Applying sciences such as demography will greatly help to cope with this growth, and thus create a sustainable future for all people of the world. Not only the science of demography, but also the study of sociology and sociological foresight can, to a large extent, prevent potential problems. Therefore, countries, especially less developed societies, today have a serious need for social studies, sociology and demography; In such a way that the population and resources can be coordinated and adjusted with each other. Otherwise, many crises await such countries; That is, a situation that will negatively affect the quality of public life. In the absence of practical guidance from dynamic theories, population concerns rely heavily on a descriptive framework called population evolution, which has been used in Europe before, and is less widely used in developed societies today (Lee: 2003).

Unequal development

While the people of the world today generally live healthier and longer lives, at the same time, there is a great deal of inequality between different segments of the population on different continents, which itself requires more attention and the application of regional and specific growth mechanisms. Because different regions and countries of the world are faced with different resources and facilities, or in other words, there are different capacities in these areas, this has caused different levels of development to appear in these areas. In such circumstances, different countries and regions of the world must always adopt plans and methods at micro and macro levels in order to improve their production capacities; In such a way that they can generally achieve a higher quality of life. Hence, many parts of the world now need proper investment in order to achieve the required economic and social development, otherwise unequal development between the countries of the world will continue.

Due to the fact that demographic change (population growth) is not the same all over the world, the fertility rate in some developing countries is high. Sociologists and economists have 


\section{Mohammad Taghi Sheykhi \\ Population and Development vs Quality of Life: A Sociological Appraisal}

proposed theories based on reproductive behavior, but these theories have not been found to be useful and effective in predicting population. If women are increasingly delaying the onset of childbirth; As the average age of childbirth increases each year, it increases the likelihood of fertility at older ages (Bongaarts: 1998). The most important reason that puts countries in a state of underdevelopment today is the high fertility in such countries; That is, a situation in which different age groups are not easily accessible to educational and welfare facilities, and in later years they will not be able to acquire the necessary skills. Hence, sociologists of the population generally recommend that a transformation from quantity to quality should take place; That means a smaller population with more facilities and ...

Most demographic change (population growth) is due to the young population that currently exists in developing countries. Today a significant share of the world's population; That is, more than a third of the population is classified as young people. This population is gradually entering the reproductive cycle; In a way that directly plays a role in population growth. Therefore, less developed countries should give high priority to their young population, in which they promote and introduce different methods of family planning and birth control; In a way that from the current young population, citizens do not appear unexpected in the coming years. In this way, the quality of life can be improved, and the needs of different groups of citizens can be met in different dimensions. It is noteworthy that more than $80 \%$ of the world's population growth today is related to less developed countries; That is, societies in which the quality of life is significantly different from global standards.

This (young) population will soon and gradually enter the fertile cycle; That means it will be responsible for more than $80 \%$ of the world's population growth. According to this forecast, governments in less developed countries should provide adequate financial support to the young population, as far as family planning programs are concerned. Global organizations such as the United Nations and its subsidiaries such as the World Health Organization, UNESCO, UNICEF, etc., advocate greater support for the young population in less developed countries; So that eventually the desired population emerges.

This means that the world's population is growing for a long time; That is, it will continue until it reaches the replacement level $(1 / 2)$ of a child for a woman. The United Nations generally recommends that families in the countries have about two children in order to achieve the desired population. UN population projections assume that even in less developed countries, fertility will slowly reach a replacement level of 1.2 children per woman by 2100 (Myrskyla et al. 2009).

In particular, about $70 \%$ of the world's future population growth (by 2050) will be in 20 subSaharan Africa and parts of Asia (excluding China). Because many population indicators in these areas are not up to standard, such as the average age of marriage less than 18, continuous population growth, high migration, low literacy, and general general poverty; Each in turn plays an important role in the population growth process. As a result, many parts of Africa today are at the forefront of population growth compared to other societies. This situation, in addition to affecting the countries concerned, also has negative and destructive effects on other societies. For example, widespread unemployment in such countries leads to large-scale migration to other communities; Like what is happening today from African countries to industrialized countries, or from Afghanistan to other countries. Thus, improving demographic indicators and ultimately population growth on the African continent can in itself lead to greater health for other communities.

\section{Fertility and Quality of Life}

Programs related to specific countries in Africa and Asia; That is, where fertility rates are still high, other countries, such as Japan and other low-fertility countries, may have different quality of life indicators. African regions and many parts of Asia due to the high level of fertility in these parts on the one hand, and on the other hand the emergence of overpopulation; This in itself causes the quality of life in these areas to be low. This situation will also negatively affect future generations as far as their quality of life is concerned. Also, since industrialized countries such as Japan and European countries have a low population 


\section{Mohammad Taghi Sheykhi \\ Population and Development vs Quality of Life: A Sociological Appraisal}

growth trend, and in contrast to the quality of life has always been on the rise in these areas, this has led to a significant distance in terms of quality of life. Exist between the continent of Africa and other industrialized countries. Although fertility and mortality have both declined during population change, due to the difference in quality of life between the First World and the Third World on the one hand, and globalization on the other, international migration, and the growth of foreign-borns in many developed countries. Has increased (National Research Council: 2000).

The promise to the developing world is that trends toward smaller families since the 1950s are related to advances in education, health care, family planning, and opportunities for girls and women in these areas; That is, what affects the quality of life. Since the second half of the twentieth century, with the advent of health, education and development projects, many less developed societies have also taken effective steps towards a higher quality of life. This has consistently made it possible for such communities to make further progress. Evidence of this claim is found in countries such as South Korea, Hong Kong, China, Taiwan, Singapore and the like in the East Asian region. Such policies are still recommended today for the less developed communities of Asia, South America, and Africa. Otherwise, human societies will face irreparable social challenges and harms in the coming decades, which, in addition to social problems, will also pose risks to the environment.

\section{Women's Rights and Quality of Life}

There are still around 215 million women in developing countries who do not have access to family planning facilities, and thus are deprived of this type of reproductive rights; That is, what directly affects their quality of life (Osotimehin: 2011). Therefore, in order to achieve a higher quality of life in its various dimensions, access to family planning programs and women's participation in decisions related to fertility and the number of children, is itself very important. Creating such a culture in developing societies is seen as a guarantee of improving the quality of life.

At the same time, of the approximately 584 million teenage girls in the world, $88 \%$ of them live in such countries; That is, points that are harmful and potentially exposed to a low quality of life. Because many developing countries in the past had high population growth rates, a significant number of girls of that period are now of marriageable age, financial independence, livelihood, and so on. In contrast, many of these countries are not sufficiently able to meet the growing needs of such girls. Therefore, the quality of life of such women is widely at potential risk.

Despite the fact that in 1994, approximately 180 countries around the world agreed to promote this type of citizenship for women, in order to prevent involuntary fertility, improve the health of women and children, and consequently the quality Enhanced life, meanwhile, many women around the world are still denied such rights. In 1994, at the ICPD, the International Conference on Population and Development in Cairo, more than 90 percent of countries agreed to give women more rights in terms of family planning and voluntary fertility programs. However, many countries have not been able to secure these rights easily. In other words, many women in such countries face problems due to high fertility, limited access to family planning services and the like; That is, the sum of the conditions that have endangered their health to a large extent. This situation has kept the quality of life of families low; That is, a situation that will have a negative impact on the next generation.

\section{Reducing Poverty and Quality of Life}

Pursuing this policy, that is, voluntary reduction of unwanted fertility, contributes to poverty reduction, and in turn improves living standards. Therefore, many countries in the world, in order to achieve a higher quality of life, have put the process of fertility decline on the agenda of their development programs, and have attached central importance to it. This situation can be seen today in many parts of Asia and Latin America. In other words, by slightly reducing the population, quality improvement in various aspects of public life can be achieved. The growth of cities and the expansion of their urbanization reflect the global transformation of poverty alleviation, and Word has been introduced to better welfare and quality of life (Glaeser: 2011). 


\section{Mohammad Taghi Sheykhi \\ Population and Development vs Quality of Life: A Sociological Appraisal}

Investing in adolescent girls in terms of education, health, protection against violence, and upgrading their skills is itself a milestone in improving the quality of life of the family. Almost universally, women with higher levels of facilities have fewer children; Simply because they want fewer children, and have better access to birth control tools (Bongaarts: 2010). Therefore, global recommendations today are that more investment, especially in meeting the needs of girls, will ultimately improve their quality of life. This situation has been extensively experienced and addressed in industrial societies throughout the twentieth century; It is a process that leads to improving the quality of life. It has already begun in Ethiopia, Guatemala, Liberia and Malawi. Because African countries have generally distanced themselves from development planning for years, international organizations, including the United Nations and its affiliates, have placed special emphasis on such countries, setting up a variety of educational and health investments for girls and women.

Such efforts, and other initiatives of this kind, protect the civil rights of women and girls insofar as they relate to their reproductive health, their education, and their quality of life. This in turn leads to a balanced approach, the use of resources in a reasonable way, and consequently the appropriate consumption of families, communities and nations.

\section{Changing Social Stratification and Quality of Life}

The past decades have witnessed economic progress in various societies such as India, China and the like. This has greatly affected the lifestyles of different groups; In such a way that tangible changes can be observed in the social stratification system of such societies. For example, the widespread migration of rural populations to their urban areas has affected various aspects of their lives socially, economically and culturally; That is, a set of factors that affect their quality of life. India, for example, has seen many economic developments in recent years; That is, rising incomes, an explosive increase in the middle class, and so on. The combination of such changes has had a great impact on the system of social stratification and even the system of shortcomings in that society. It brings with it a different lifestyle and new expectations for families and individuals. Given the emergence of such a situation, social planners must always adopt appropriate and convincing policies. Otherwise, a kind of disorder appears in different dimensions within such societies.

The growth and development of the market, consumption, stores, domestic airlines and the like, itself indicates the change of social classes in this country; That is, a situation that has affected the quality of life in various dimensions. Economic development generally leads to more consumption, more relocation, more services, and so on; That is, what is called a higher quality of life today. Industrial societies have gone through such a process in the past; That is what has put them in a higher state of well-being and quality of life today. The desirability of quality of life today positively affects future generations themselves; That is, it creates a kind of guarantee for them.

At the same time, there are still many signs of relative poverty in places like India. For example, people living below the poverty line in urban areas refer to those who have access to less than 2,400 calories of food per day, and in rural areas this indicator is defined as less than 2,100 calories per person per day. Therefore, countries should consider their urban and rural areas in a balanced way as far as their food supply is concerned. Otherwise, there will be more migration to urban areas that have more food security and services.

This change in social classification, incomes, and consumption has itself led to better living conditions, more services, and ultimately a higher quality of life for newcomers. As a result, socio-economic leaders and planners today have heavier responsibilities around the world; In a way that can meet the growing needs of their citizens; That is, providing various services, providing employment, providing housing in the form of (small) nuclear settlements, providing leisure facilities and the like.

\section{Conclusion}

Sociologically speaking, population and development have an indirect relationship with quality of life. As countries are widely becoming urban, people seek more quality of life. New lifestyles emerging since 1970, caused the discussion of quality of life. Since then, people tried to acquire the criteria reflecting quality of life. Access to more education, health measures, hygiene, insurance, better conditions for women, lower child birth rate and the like, came to be known as the indicators of quality of life. For that, there came to be a competition among different nations. To attain that, many people adopted new measures and policies. Similarly, 


\section{Mohammad Taghi Sheykhi}

Population and Development vs Quality of Life: A Sociological Appraisal

new development plans were put into action, and following it, new industries and technologies were created and used in order to reach higher quality of life. Therefore, quality of life is something made, and not given by nature.

\section{References}

- Bongaarts, J. and F. Feeney, Population and Development Review, 24, 271 (1998). CrossRef

- Bomgaarts, J. et al., 2010, Population Research, 31 (2010).

- Boserup, E., 1981, Population and Technological Change, Chicago: University of Chicago Press.

- Damien, Cave., 2021, Long Slide Looms for World Population, With Sweeping Ramifications, The New York Times.

- Esteban, O., 2013, World Population Growth, Our World in Data, Archived from the Original, 13-Oct-2016.

- Glaeser, E., 2011, Triumph of the City, New York: Penguin Press.

- Lee, R., Journal of Economic Perspectives, 17, 167 (2003). CrossRef

- Myrskyla, M., et al., Nature, 460, 471 (2009). CrossRef

- National Research Council, Commission on Behavioural, Social Sciences and Education, Beyond Six Billion: Forecasting the World Population, J. Bongaarts, and R.A Bulatao, Eds. Washington DC. (National Academics Press 2000).

- Osotimehin, B. 2011, Population and Development, UNFPA., New York. CrossRef

- Population and Development Review, population Council, Wiley Blackwell, Vol.38, No.4, pp.730, 2012.

- The Lottery of Life--Where to be born in 2013. The Economist, Nov 21, 2012.

- United Nations, World Population Prospects: The 2010 Revision, Vol.1, Comprehensive Tables (United Nations, New York, 2011). CrossRef

- World Population Prospects, 2016, Population Division- United Nations, Archived from the Original. 